\title{
IMPLEMENTING CONSTRUCTIVISM LEARNING THEORY IN ONLINE TUTORIAL
}

\author{
Benny A. Pribadi \\ Anis Surtiani \\ Ichwan \\ Universitas Terbuka \\ e-mail: agus.benny@gmail.com
}

\begin{abstract}
The advanced development of information and communication technologybrings a significant impact on the way of how human learn. The e-learning orlnternet-based and online learning has been widely used in a variety of learning activities as a suplement to the conventional in-class learning, flipped classroom etc. The term e-learning refers to learning activities conducted by the use ofInternet. Universitas Terbuka (UT) utilizes e-learning program in the form of online tutorial. The online tutorial is basically a form of learning support provided by UT to facilitate student to learn. The online tutorial consists of three major learning activities including reading, discussion and assignment. During online tutorial student must complete the assigned activities and interaction with peers, tutor and digital learning resources. Online tutorial can be seen as an instrumental tool that provide an opportunity for students to expandhis/her knowledge and skills beyond the provided printed and digital module. Tutors should be able to design online learning programs that can be used to facilitate students in expanding their knowledge and skills. The purpose of this study is to elaborate conceptually the use of constructivism learning theory in online tutorial of the open and distance learning higher institution.
\end{abstract}

Keywords: constrctivism, e-learning, learning theory

\section{BACKGROUND}

Rapid development of information and communication technologies provides a significant impact on the way human learning. Currently, the term of e-learning-web-based and online learning-is widely used in a variety of learning activities. The term e-learning refers to learning activities conducted through the Internet.

Model of e-learning can provide wide access for individuals to acquire knowledge and skills from a variety of learning resources that are available digitally. Through online learning student or learner can actively extracting knowledge and skills in accordance with learning needs.

Online learning is a term used to describe distance learning delivered via the Internet. This mode of learning can be used as a relevant tool to improve the public access to quality education. The implementation of distance education system relies heavily on the use of media and take advantage of online learning technology for interaction with students. Utilization of online learning enables ongoing learning interaction either synchronous or asynchronous. In the distance education system, e-learning has been used as one of the effective ways to deliver the content or subject matter. 
Universitas Terbuka or UT implements and utilizes e-learning program in the form of an online tutorial (Tuton). Tuton is basically a form of learning support provided by UT to facilitate the learning process of its students. In the tutorial activity the student must perform intensive interaction with the tutor and available digital learning resources.

Online learning can be seen as an instrument that can provide an opportunity for students to build and construct the knowledge and skills. Tutors should be able to design online learning programs that can be used to facilitate students in expanding their knowledge and skills. The purpose of this study is to elaborate conceptually the use of constructivism learning theory in online tutorial of the open and distance learning higher institution.

\section{Literature review}

The development of information and communication technologies that took place rapidly make more widespread use of the internet networks. This has implications for individual greater access to utilize various sources of information. Nowadays learning is no longer depend on a limited learning resources as was in the past. Teachers and students can take advantage of a variety of richer digital learning resources.

Duffy and Mc. Donald (2011) in this case, noted that: "... by the use of computer networks orthe Internet students as users will have access to enormous sources of information and knowledge required to build competencies. Teachers and students may share information and knowledge available in internet. (p. 233-234).

The use of electronic mail or e-mail and the web has become a means of learning and communication which are inseparable in everyday life. The use of e-mail plays an important role in the exchange of information or knowledge sharingfor its users. Websites have very crucial functions as location of information and knowledge required by the user.

Learning through the Internet and the web, which is known as online learning, is now expanding its use. Various educational institutions take advantage of online learning as a means to transform and to deliver content or substances to the students. Online learning activities are not only fully implemented or fully online learning but also blended with face-to-face learning activities.

There are five main reasons underlying the growth of online learning. Those are: (1) access; (2) efficiency; (3) stability; (4) costs; (5) technology. The growth of online learning activities both at the college level as well as at secondary school level has been showed to be high aspirations to obtain educational services among the community. The expansion of learning opportunities through the use of online learning provide opportunity for the community to improve the career and acquire new knowledge and skills (http://www.wisegeek.com/what-is-online-learning.htm).

The use of online facilities in learning activitiesprovide multiple benefits to both teachers and students. Aspilera (2010) notedsome advantages of using online learning such as: (1) Convenience and flexibility; (2) Student enrichment; (3) Cost-effective choices. (http://www.worldwidelearn.com/ education-articles/benefits-of-online-learning.htm).

Learning activities delivered through online provide opportunities for students to explore and discover knowledge from various online sources. The use online learning requires the students to: (1) to be active in exploring relevant knowledge; (2) commit and consistent in finishing assignments or tasks; (3) follow the schedule and learning activies; (4) participate actively in discussion of the importance topics. 
Teachers and students has to be able to select relevant and credible content or subtances to be learned. Intensive discussion should be based on the selected topic. This will help students to construct knowledge and skills required to attain the course competencies.

\section{Online tutorials in distance education system}

Recently major open and distance learning institutions apply online learning to deliver the content to the students. The use of online learning as a mode of communication bridges geographical distant between teachers and students. The term online learning is often interpreted as a form of distance education where learning materials delivered through the computer networks. In this sense online learning can be viewed as a medium of communcation between the tutor, as source of knowledge and information, and the students.

Implementingonline learning properly will help students to interact actively in order to gain knowledge and information several learning sourcesfrom available webs. Webs, which are selected and used wisely, provide rich content that can be used as meaningful learning materials. The use of online learning programs requirethe tutors to do several tasks such as:

a) Select approprate and meaningful content to be learned by the students;

b) Design the content to be delivered and learned by students;

c) Develop and produce the content to be learned effectively by the students;

d) Implement the develoved online materials to students;

e) Evaluate formatively the material delivered througe online;

f) Revise online learning based on formative evaluation results.

The use of online learning closely related to the students activities in constructing knowledge and skills. Online learning programs in this sense enable the students to interact with tutors, students and also specific learning materials, intensive online learning interaction between tutor and students and students will facility student to construct required learning materials.

\section{Constructivism in online learning}

In order to create effective online learning programs it is necessary for the tutors to apply the approprate learning theory. One of the learning theories which is suitable to be appiied in online learning is constructivism learning theory. The Application of constructivist learning theory requires the instructor to encourage students to analyze, interpret, and predict knowledge and information. To make the students able to construct knowledge and skills effectively, the instructor needs to ask challenging questions that can provoke students' thinking process.

In other words, the instructor needs to conduct an intensive online dialogue with the students. The process of knowledge construction will take place through intensive dialogues between the learners and instructors or other learners. In doing learning activities, the student cannot be treated as an empty or black box that is ready to receive any information and knowledge submitted by an instructor.

Students cannot be regarded as passive objects that act only as receivers of information. Students must be regarded as individuals who are active in the learning process. Students need to confirm their ideas and skills through relevant learning. In order to encourage students to build knowledge, teachers have to present a good combination of concrete and abstract knowledge. Experts suggested that the constructivist learning require the reconceptualization of the learning process. 
The role of the teacher in the constructivist learning activities is to encourage and directthe students to poses new meaning of learning experience and information experience. Active learning techniques should be used to help students build knowledge being studied. Such techniques include the experimental activities and real problem solving. Both activities can be applied to ensure the students to be able to create knowledge. Construction of knowled and science reflected in the students behavior the students will give a new meaning to their learning experience.

To be able to assist and guide the process of construction of knowledge in students, teachers need. Besides, the teachers have to judge positively students' understanding related to concept and knowledge. The learning process takes place in an atmosphere of dialogue between the source of the learners Constructed.

Students have to be taught the a dialogue to understand the content. By asking themselves, students will become builders of knowledge. Constructive classroom situation needs to be designed so that students are able to perform learning activities HOW TO LEARN. Learning is essentially a process that can take students to be able to see things from a new perspective. Implementing constructive approach requires the following learning principles such as;

- $\quad$ Encourage students as learners to be able to solve a problem that is new.

- $\quad$ Assist students in integrating science who has been studied.

- $\quad$ Motivate students or learners to be able to create new knowledge for himself.

Implementation of constructivist approach in the learning activities require the involvement of the student to always ask, analyze, interpret, and predict and test understanding of concepts. The role of a tutor or instructor in this case is to be a facilitator that encourages the process of students knowledge constructions.

Implementation of constructivism approach in the distance learning system can be done by integrating the main principles of constructivism in learning materials, provision of learning or tutorial programs and organizing examinations.

The purpose of using constructivist approach is to facilitate students to have the ability to find, understand, and use information or knowledge which is learned. Implementation of constructivist approach in learning activities has some important characteristics, such as;

- $\quad$ Active learning.

- $\quad$ engage students authentic learning activities.

- $\quad$ make learning activities more interesting and challenging.

- Integrate new information with the information that has been learnedwhich is called "bridging".

- $\quad$ Students should be able to reflect on the knowledge being studied.

- $\quad$ Teachers work as a facilitator who can assist students in making the construction of knowledge. In this case, the teacher is no longer merely act as a presenter of information.

- $\quad$ Teachers should be able to provide assistance in the form of scafolding required by students in taking the learning process.

Scafolding can be interpreted as support given to students during their learning process. The aim of using scaftolding is to ensure that students' understandthe content or learning materials. Support and assistance that can be given to students during their learning process can be: (1) Flagging (prompts or clues); (2) Explanation; (3) Demonstrations; (4) Personal training or coaching; (5) provide additional learning resources.

Internal processes such as Piaget's theory of organization, assimilation and accommodation affect the construction process knowledge. The new knowledge is an abstraction and construction of old knowledge. Knowledge is not a mirror of reality, but an abstraction that grows and develops 
together with cognitive activity. Knowledge is not just things that are right or wrong, but grows from within the individual through the process of development.

A number of cognitive learning theorists view learning as an active process. In contructive learning process, the students not only receive information, but also trying to find new information that could be used in solving a problem. Besides, the students also need to reconstruct the information and knowledge that has been studied to reach a new understanding.

Woolfolk (2004) suggests three theories about the construction of knowledge in learning activities. Construction of knowledge within the individual is influenced by several factors: how people process information and knowledge; internal processes and external processes; and the combination of internal and external factors.

Reality or fact contained in the external world will affect the construction of knowledge. In this individual learning theory to reconstruct the facts obtained from the outside world through mental representations accurate as making preposition network, concepts, patterns of causal conditions and rules of action. This view is more inclined and associated with learning theory information processing learning theory.

Internal factors together with external factors influence the process of formation or construction knowledge. Knowledge is growing due to internal factors (cognitive) and external factors (environmental and social). Knowledge arranged because of the social interaction between individuals with the experience that comes from the surrounding environment.

Knowledge is a reflection of the experience and the external world are influenced by culture, language, belief, interaction with others, direct instruction and modeling. Guidance, discovery, learning experiences, models, training, belief and prior knowledge greatly affect an individual's success in doing the learning process.

Cruickshank and friends (2006) suggested some steps that need to be done in implementing constructuvism approach to learning. Several steps can be used through several learning stages: preparation; delivery of content; closing.

The preparation phase is done in implementing the constructivist approach to learning consists of several activities, such as: (1) Determine the learning objectives; (2) Explains how to achieve the learning objectives; (3) Describe how to classify the subject matter; (4) Tells how to associate new information with the information that has been previously owned; (5) Gather ingredients useful information; (6) Describe how reflection.Delivery of contens consists of the following steps such as: (1) Ensuring that students strive to achieve the goal of learning and interaction with colleagues; (2) Ensure that students perform mutual cooperation and contribute in taking the learning process.

Closing stages that ensure that students have to learn new knowledge which is different from previous knowledge.

\section{CONCLUDING REMARK}

Learning is a process that requires planning in order to achieve the desired goals. According to Woolfolk (2007) The characteristics of the learning plan that reflects the implementation of constructivist approach has differences with other forms of learning approaches in terms of: (1) the use of primary sources, the formulation of hypotheses, and involvement in the learning process that is systematic; (2) efforts to deal with the viewpoint the a different perspective; (3) be a careful reader and active writer: (4) courageous and able to face problems.

(There are a number of reasons or rationale underlying the implementation of constructivist approach 
in the learning activity. Duffy, Cunningham, Jonassen (1996) noted several reasons of using constructivist approach in the learning process, such as: (1) All knowledge and learning is a construction process; (2) Knowledge is a construction events experienced from various viewpoints or perspectives; (3) The learning process should take place in a relevant context; (4) Learning can take place through the medium of learning; (5) Learning is an activity that is inherently social dialogue; (6) Students have a variety of backgrounds multidimensional; (7) Know what you already know is a major achievement in learning.

\section{REFERENCES}

Cruickshank. Donald R, Deborah B. Jenkin, \& Kim K. Metcalf. (2006). The Act of Teaching. New York Mc Graw Hill.

Jonassen, David H. (ed). (1996). Handbook of Research for Educational Communication and Technology. New York: Macmillan Library Reference. 1996.

Woolfolk Anita. (2004). Educational Psychology. New York: Pearson.

Woolfolk Anita. (2007). Educational Psychology. New York: Pearson. 